\title{
VARIATIONS IN PULMONARY FISSURES: AN ANATOMICAL STUDY
}

\author{
Jyothi Lakshmi G.L. *1, Bharathi D ${ }^{2}$, Sarala H.S ${ }^{3}$.
}

${ }^{* 1,2,3}$ Assistant Professor, Department of Anatomy, Rajarajeshwari Medical College and Hospital, No.202, Kambipura, Mysore Road, Bangalore, Karnataka, India.

\section{ABSTRACT}

Background: Pulmonary fissures are invaginations of the visceral pleura that extend from the outer surface of the lung into its substance. The fissures are grouped into normal and accessory fissures. The oblique fissure and horizontal fissures are the normal pulmonary fissures which may be complete, incomplete or absent. Incomplete pulmonary fissures are considered to be markers of collateral ventilation. They play a significant role in determining clinical response following valve replacement surgery in emphysematous patients. The Accessory fissures occurring within an individual lobe may be confused with other lesions such as linear atelectasis, pleural scar. Knowledge of the variations in the pulmonary fissures is useful for clinical interpretation. It is in this regards that this study was undertaken to assess the morphology of pulmonary fissures.

Materials and methods: The study was conducted on 60 formalin preserved adult human lungs (32 right, 28 left) of unknown age and sex obtained during dissection of embalmed cadavers for undergraduate teaching in Department of Anatomy, Rajarajeswari medical college and hospital. The anatomical classification proposed by Craig and Walker is followed to determine the completeness of pulmonary fissures. Four grades of fissures have been described. Grade 1- complete fissure with entirely separate lobes. Grade 2- complete visceral cleft but parenchymal fusion at the base of the fissure. Grade 3 - visceral cleft evident for a part of the fissure. Grade 4 complete fusion of lobes with no evident fissure line. The data was tabulated and analysed using descriptive statistics. The study was undertaken after obtaining approval from the institutional ethics committee.

Results: Oblique fissure was incomplete in $13.33 \%$ of the right lungs while horizontal fissure was found to be incomplete in $30 \%$ of the right lungs. Horizontal fissure was found to be absent in $2(3.33 \%)$ of the right lungs. A superior accessory fissure in the lower lobe separating the upper part of the lobe from the rest of the basal segments was found in one right lung .

Conclusions: The present study shows that the horizontal fissure is more frequently incomplete or absent when compared to the oblique fissure in the right lung. Superior accessory fissure in the lower lobe of a right lung was observed in 1 (1.66\%) specimen. Knowledge of the varying degrees of completeness of pulmonary fissures and accessory fissures is essential to avoid misinterpretation of radiological signs.

KEY WORDS: Pulmonary Fissure, Oblique Fissure, Horizontal Fissure, Incomplete Fissure, Superior Accessory Fissure.

Address for Correspondence: Dr.Jyothi Lakshmi G.L., Assistant Professor, Department of Anatomy, Rajarajeshwari Medical College and Hospital, No.202, Kambipura, Mysore Road, Bangalore-560 074, Karnataka, India. E-Mail: drjyothilakshmigl@gmail.com

Access this Article online

Quick Response code

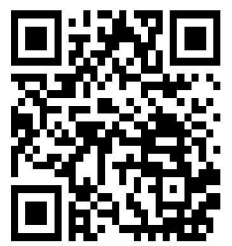

DOI: $10.16965 /$ ijar.2018.254

Journal Information

International Journal of Anatomy and Research

ICV for 2016 ISSN (E) 2321-4287 | ISSN (P) 2321-8967

90.30

https://www.ijmhr.org/ijar.htm

DOI-Prefix: https://dx.doi.org/10.16965/ijar

Article Information

Received: 19 May 2018

Peer Review: 21 May 2018

Revised: None
Accepted: 02 Jul 2018

Published (O): 05 Sep 2018

Published (P): 05 Sep 2018

\section{INTRODUCTION}

Fissures are invaginations of the pleura that extend from the outer surface of the lung into its substance. They are traditionally considered in two groups: normal fissures that separate the lungs into the three right-sided and two left- 
sided lobes and accessory fissures that occur within one of the lobes [1]. The pulmonary fissures may be complete, incomplete or absent. The oblique fissure extends from the surface of the lung to the hilum and divides the organ into separate upper and lower lobes which are connected only by the lobar bronchi and vessels. On the right lung a horizontal fissure passes from the anterior margin into the oblique fissure to separate a wedge-shaped middle lobe from the upper lobe [2].

Incomplete fissures may alter the usual patterns of collapse seen in patients with endobronchial lesions. An incomplete major fissure causes an odd appearance of fluid tracking within the fissure in pleural effusion [3].

Presence of accessory fissures in lung specimens is not uncommon, but it is difficult to appreciate them on radiographs and CT scans hence they are either not appreciated as distinct entities or are completely misinterpreted [4].

Knowledge of the variations in the pulmonary fissures is useful for clinical interpretation. It is in this regards that this study was undertaken.

Aim of the Study: To study the morphology of pulmonary fissures.

Objectives of the Study: To assess the extent and completeness of the oblique and horizontal pulmonary fissures and to assess the extent of accessory fissures.

\section{MATERIALS AND METHODS}

The study is conducted on 60 formalin preserved adult human lungs (32 right, 28 left) of unknown age and sex obtained during dissection of embalmed cadavers for undergraduate teaching in Department of Anatomy, Rajarajeshwari medical college and hospital.

Inclusion criteria: Normal adult human lungs

Exclusion criteria: Lung specimens with pathological lesions, lungs damaged during removal.

The approval for the study was obtained from the institutional ethics committee. The specimens were observed for the presence and completeness of normal fissures and accessory fissures.The anatomical classification proposed by Craig and Walker, as quoted by Meenakshi et al [5] is followed to determine the complet- eness of pulmonary fissures. Four grades of fissures have been described.

Grade 1-complete fissure with entirely separate lobes.

Grade 2- complete visceral cleft but parenchymal fusion at the base of the fissure.

Grade 3 - visceral cleft evident for a part of the fissure.

Grade 4 - complete fusion of lobes with no evident fissure line.

The data was tabulated and analysed using descriptive statistics.

\section{RESULTS}

Out of 60 lungs, 32 lungs belonged to the right side and 28 lungs to the left side. The pattern of the fissures observed is as shown in the Tab. 1. The classification of the fissures based on Craig and Walker's criteria [1] is shown in Table 2.

Oblique fissure was incomplete in $13.33 \%$ of the right lungs while horizontal fissure was found to be incomplete in $30 \%$ of the right lungs. Horizontal fissure was found to be absent in 2 (3.33\%) of the right lungs (Fig. 1). A superior accessory fissure in the lower lobe separating the upper part of the lobe from the rest of the basal segments was found in one right lung (Fig.2).

Among 28 left lungs, accessory fissures were noted in 2 specimens. An accessory fissure was noted near the apex of a left lung. The fissure was incomplete, ran horizontally across the apex of the upper lobe, it did not communicate with the left oblique fissure (Fig.3).

In a specimen of the left lung, an incomplete oblique fissure belonging to Class III group under Craig and Walker's that partially separated the upper and lower lobes was noted (Fig. 4). The two lobes of the lung were fused in the upper part and were partially separated by the fissure in the lower part.

Table 1: The pattern of pulmonary fissures in the present study $(n=60)$.

\begin{tabular}{|c|c|c|c|}
\hline & Complete & Incomplete & Absent \\
\hline Right Lung (32) & & & \\
\hline Oblique fissure & $24(40 \%)$ & $8(13.33 \%)$ & - \\
\hline Horizontal fissure & $12(20 \%)$ & $18(30 \%)$ & $2(3.33 \%)$ \\
\hline Left lung (28) & & & \\
\hline Oblique fissure & $11(18.33 \%)$ & $17(28.33 \%)$ & - \\
\hline
\end{tabular}


Table 2: Classification of the oblique fissure based on Craig and walker's criteria.

\begin{tabular}{|c|c|c|c|c|}
\hline Oblique fissure & Grade I & Grade II & Grade III & Grade IV \\
\hline Right Lung & 24 & 6 & 2 & - \\
\hline Left lung & 11 & 15 & 2 & - \\
\hline
\end{tabular}

Table 3: Comparison of pulmonary fissural pattern in different studies.

\begin{tabular}{|c|c|c|c|c|c|c|}
\hline & $\begin{array}{c}\text { Varalakshmi et al, } \\
2014 \text { [7] }(n=64)\end{array}$ & $\begin{array}{c}\text { Ambali et al, } \\
2014[8](n=100)\end{array}$ & $\begin{array}{l}\text { Thapa et al, } \\
2016[9](n=40)\end{array}$ & $\begin{array}{l}\text { Gopalakrishna et al, } \\
2017[10](n=100)\end{array}$ & $\begin{array}{l}\text { Shivleela et al, } \\
2017[11](n=84)\end{array}$ & $\begin{array}{c}\text { Present study } \\
\mathrm{n}=60\end{array}$ \\
\hline \multicolumn{7}{|c|}{ Right Oblique fissure (\%) } \\
\hline Incomplete & 16.7 & 14 & 30 & 14 & 63 & 13.33 \\
\hline Absent & 0 & 4 & 0 & 0 & 1 & - \\
\hline \multicolumn{7}{|c|}{ Right Horizontal fissure (\%) } \\
\hline Incomplete & 30 & 28 & 50 & 20 & 63 & 30 \\
\hline Absent & 10 & 8 & 20 & 6 & 26 & 3.33 \\
\hline \multicolumn{7}{|c|}{ Left Oblique fissure (\%) } \\
\hline Incomplete & 29 & 18 & 25 & 8 & 70 & 28.33 \\
\hline Absent & 3 & 4 & 15 & 6 & 9 & - \\
\hline
\end{tabular}

Fig. 1: Absent horizontal fissure in right lung.

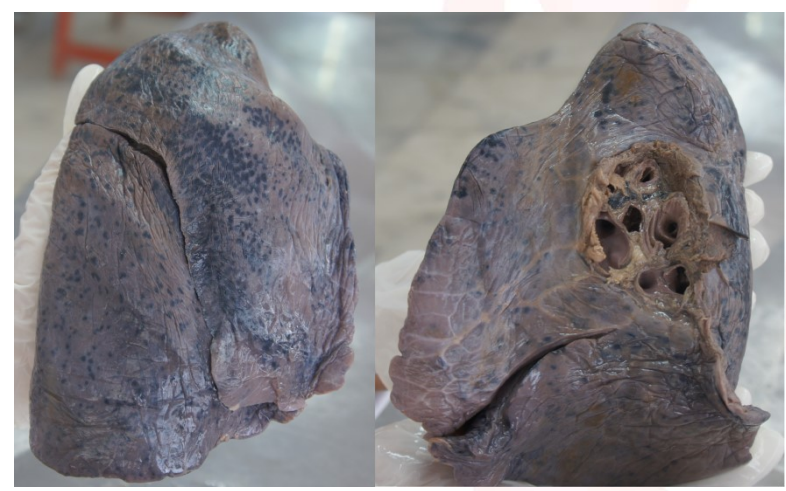

Fig. 2: A superior accessory fissure in the lower lobe of the right lung separating the upper part of the lobe from rest of the basal segments

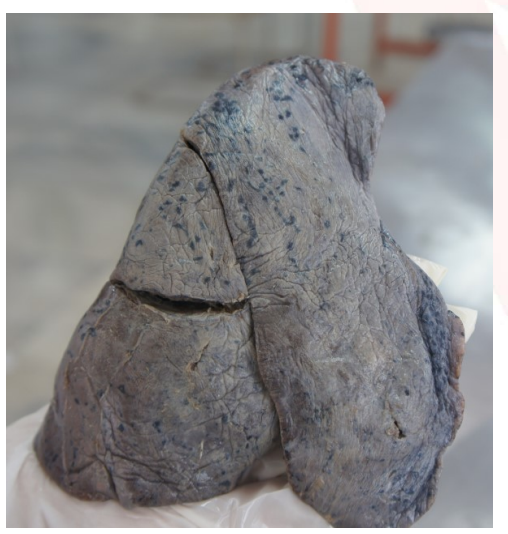

Fig.3: An accessory fissure near the apex of left lung.

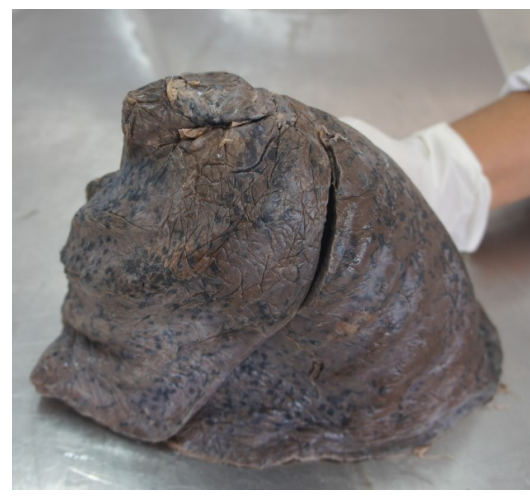

Int J Anat Res 2018, 6(3.3):5597-01. ISSN 2321-4287
Fig. 4: Incomplete oblique fissure of left lung.

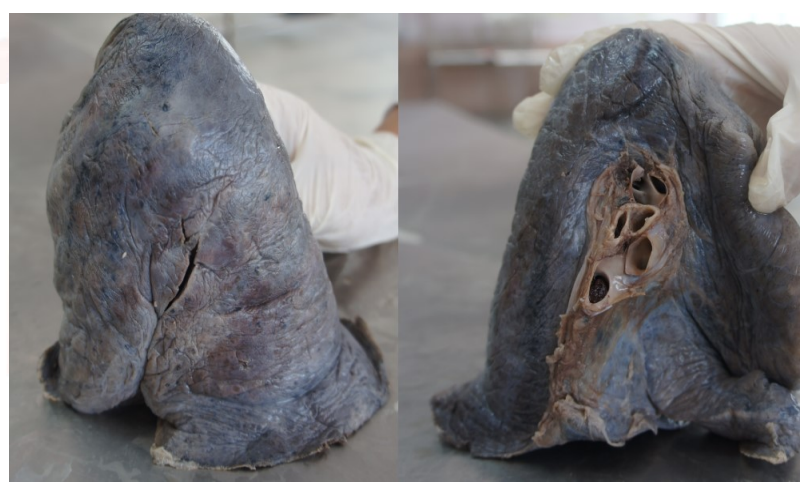

\section{DISCUSSION}

The oblique fissure is also known as the Major fissure. The oblique fissures of each lung are indicated by a line joining the spine of the T3 vertebra, which is opposite the posterior end of the fifth rib, to the sixth rib in the midclavicular line. More simply, this is approximately the line of the fifth rib, or level with the vertebral border of the scapula when the arm is fully abducted above the head [2].

The horizontal fissure is also known as the Minor fissure. The middle lobe of the right lung may not be completely separate from the upper lobe, the fissure separating it from the upper lobe being incomplete or even absent. The fourth costal cartilage overlies the horizontal fissure between the upper and middle lobes; continued horizontally this line meets the oblique fissure in the midaxillary line [2].

Horizontal fissure was more frequently found to be incomplete when compared to the oblique fissure of right lungs in our study (Table 1). This finding is similar to the results of other studies 
as shown in Table 3 [7-10]. The horizontal fissure was absent in $2(3.33 \%)$ right lungs while the oblique fissure was present in all the specimens. Our findings is similar to that of Raasch et al [6] who opined that incompleteness of the minor fissure was far more common than the incompleteness of any portion of either major fissure. Fusion was more common and usually more extensive between the middle and upper lobes (across the minor fissure) than between the middle and lower lobes (across the major fissure) [6]. Development of incomplete fissures may be attributed to the influence of genetic and environmental factors during the development of lung.

An incomplete major fissure causes an odd appearance of fluid tracking within the fissure in pleural effusion. Also, pneumonia may spread to adjacent lobes though the incomplete fissures. Odd lobar involvement with carcinoma of the lung may be explained on a similar basis [3]. Interlobar collateral ventilation is due to the absence of interlobar lung fissures with consequent anatomical and functional communication between the lobes. Thus, incomplete interlobar fissures and interlobar collateral ventilation are strictly related to one another [12]. Incomplete fissures may alter the usual patterns of collapse seen in patients with endobronchial lesions. Due to incomplete fissures, collateral air drift may keep the obstructed lobe aerated even though the bronchus supplying the lobe is obstructed [3].

Gompelmann et al [13] in his review concluded that completeness of interlobar fissures is a crucial factor in predicting a good clinical outcome following valve treatment in patients with emphysema. Also, that the incomplete interlobar fissures can be considered as markers of collateral ventilation.

Taverne $Y$ et al. opined that perioperative identification of the completeness of fissures is imperative before performing lobectomy to prevent postoperative air leakage [14].

Anatomically, an accessory fissure is a cleft of varying depth lined by visceral pleura. Radiographically its appearance is similar to oblique and horizontal fissures, except for the location [6]. Accessory fissures correspond to the planesof division between bronchopulmonary segments and account for many of the previously reported accessory lobes [15].Accessory fissures can be mistaken for interlobar fissure, a scar, the wall of a bulla, or a pleural line made visible by pneumothorax [6].

The most common accessory fissures are the azygos, inferior, and superior accessory fissures and the left minor fissure [1].The inferior accessory fissure separates the medial basal segment from the remainder of the lower lobe [1].The cardiac lobe is the medial basal segment of the lower lobe, which is demarcated by the inferior accessory fissure [15].

The superior accessory fissure separates the superior segment of the lower lobe from the basal segments. When it is present, the superior segment has been called the posterior or dorsal lobe. The fissure lies at about the same level as or slightly lower than the horizontal fissure[16].

In our study, we came across a specimen of right lung with the superior accessory fissure in the lower lobe. Horizontal fissure was found to be absent in the specimen.

The azygos fissure is created by downward invagination of the azygos vein through the apical portion of the right upper lobe. It is manifested radiographically as a curvilinear tear drop shadow caused by the azygos vein itself. Because the vein runs outside the parietal pleura, four pleural layers (two parietal and two visceral) form the fissure. The fissure is visible on about $0.5 \%$ of chest radiographs [1].The azygous fissure is almost invariably in the right lung, although left azygous fissures have been reported with the vein at the base of the fissure being the left superior intercostal vein[16]. In the present study an accessory fissure was noted near the apex of a left lung. The fissure was incomplete, ran horizontally across the apex of the upper lobe.

Accessory fissures may be confused with areas of linear atelectasis, pleural scars,or walls of bullae. Presence of accessory fissures in lung specimens is not uncommon, but it is difficult to appreciate them on radiographs and CT scans hence they are either not appreciated as distinct entities or are completely misinterpreted [4]. 


\section{CONCLUSION}

The present study shows that the horizontal fissure is more frequently incomplete or absent when compared to the oblique fissure in the right lung. Superior accessory fissure in the lower lobe of a right lung was observed in 1 (1.66\%) specimen. Knowledge of the varying degrees of completeness of pulmonary fissures and accessory fissures is essential to avoid misinterpretation of radiological signs.

\section{Conflicts of Interests: None}

\section{REFERENCES}

[1]. Muller NL, Silva C Isabela S. Imaging of the Chest. Volume 1. Saunders; 2008: 6-18.

[2]. Sinnatamby CS. Last's Anatomy. Regional and Applied. $12^{\text {th }}$ Edition. Elsevier.Churchill Livinstone; 2012: 214-218.

[3]. Tarver RD. How common are incomplete pulmonary fissures, and what is their clinical significance? Am JRoentgenol 1995; 164(3):761.

[4]. Godwin JD, Tarver RD. Accessory fissures of the lung.AJR Am J Roentgenol 1985; 144(1):39-47.

[5]. Meenakshi S, Manjunath KY, Balasubramanyam V. Morphological variations of the lung fissures and lobes. Indian J. Chest. Dis. Allied Sci. 2004;46: 179182.

[6]. Raasch BN, Carsky EW, Lane EJ, O Callghan JP, Heitzman ER. Radiographic anatomy of the interlobar fissures: A study of 100 specimens. AJR 1982; 138 : 1043-49.

[7]. Varalakshmi KL, Jyothi NN, Sangeetha M. Morphological variations of fissures of lung. Indian J Appl Res 2014;4:457 69.

[8]. Ambali MP, Jadhav SD.; Doshi MR, Patil; Roy P, Desai RR. Variations of Lung Fissures: A Cadaveric Study. Journal of Krishna Institute of Medical Sciences University. 2014; 3(1):85-89
[9]. Thapa P, Desai SP. Morphological variation of human lung fissures and lobes: An anatomical cadaveric study in North Karnataka, India. Indian j health sci 2016;9:284-7.

[10]. Gopalakrishna K, Deepalaxmi S, Somashekara S C, Rathna B S. A cadaveric study on morphological variations of fissures and lobes in the human lungs and its clinical significance. J Exp Clin Anat 2017;16:7-11.

[11]. Shivaleela C, Lakshmiprabha S, Afroze M K H. A study of anatomical variations in patterns of fissures and lobes in human lungs: a cadaveric study with clinical significance. Int J Anat Res 2018;6(1.1):4819-4823.

[12]. Diso D, Anile M, Carillo C, et al. Correlation between collateral ventilation and interlobar lung fissures. Respiration. 2014;88(4):315-319

[13]. Gompelmann D, Heussel CP, Eberhardt R, et al. Efficacy of bronchoscopic thermal vapor ablation and lobar fissure completeness in patients with heterogeneous emphysema. Respiration 2012;83:400-6.

[14]. Taverne Y, Kleinrensink GJ , Rooij PD. Perioperative Identification of an Accessory Fissure of the Right Lung. Case reports in pulmonology 2015.

[15]. Patterson, GA, Cooper JD, Deslauriers J, Lerut A, Luketich JD, Rice TW, Pearson FG. Pearson's Thoracic and Esophageal Surgery . $3^{\text {rd }}$ Edition. Churchill Livingstone; 2008: 401-414.

[16]. Cronin P, Gross BH, Kelly AM, Patel S, Kazerooni EA, Carlos RC .Normal and accessory fissures of the lung: evaluation with contiguous volumetric thinsection multidetector CT. Eur J Radiol.2010; 75:1-8.

How to cite this article:

Jyothi Lakshmi G.L., Bharathi D, Sarala H.S. VARIATIONS IN PULMONARY FISSURES: AN ANATOMICAL STUDY. Int J Anat Res 2018;6(3.3):5597-5601. DOI: 10.16965/ijar.2018.254 